\title{
STUDY ON THE TRANSITION FROM THE LINEAR ECONOMY TO THE CIRCULAR ECONOMY
}

\author{
Cezarina AFTENI ${ }^{1}$, Viorel PAUNOIU ${ }^{1}$, Mitica AFTENI ${ }^{2}$
}

${ }^{1}$ Department of Manufacturing Engineering, "Dunarea de Jos" University of Galati, Romania

${ }^{2}$ Rulmenti S.A., Barlad, Romania

Email: Cezarina.Afteni@ugal.ro

\begin{abstract}
In the actual economic environment, it is more and more important for people to be aware of their impact on environmental aspects, consumption of natural resources and usage of resources several times by recycling and reuse at the initial intended usage or changing the place of usage in opposition to the principle of owning, using and then throwing away. The increasing of waste quantities are the direct consequences of consumption that exceeds real needs and, at the same time, alters the state of the environment as the main provider of resources. In the coming years, approaches of the products' design and built must be focused to allow for the continued reuse of resources. The introduction of the circular economy is a challenge to the linear economy approach to resource production and consumption. The circular economy is an economy that produces zero waste. The circular economy concept is not so new. European and world decision-making communities have been circulating for years the concept of circular economy, but only now the concept is beginning to gain visibility and applicability. In this paper, a study on the transition of companies from the linear economy to the circular economy is developed. Starting from the fact that current global sustainable development is given special attention, based on the transition from linear to a circular economy, the study provides an image of the degree of knowledge on the concept of circular economy of private companies, highlighting the major discrepancies between the linear and the circular economy, as well as the multidimensional impact of the implementation of the circular economy. It is necessary for more and more companies to experience how the circular economy can help them in the extraction and transport of raw materials, materials and product design, production, distribution, and consumption of goods, repairs, remanufacturing schemes and reuse, waste management and recycling.
\end{abstract}

KEYWORDS: circular economy, resource computation, zero waste, sustainable development.

\section{INTRODUCTION}

The circular economy is an evolving concept and is considered a necessary and pragmatic solution for reconciling the link between the pace of economic growth and the pressure on resources provided by the environment.

The process of knowledge always oscillates between theory and practice, between analysis and synthesis, which justifies the theoreticalmethodological and practical approaches occasioned by the debates on the concept of circular economy, [1].

In the current context of the linear economy, the processes are quite clear: companies design the products, buy raw materials, transform raw material in final products through production processes, and after all the inspections are finished the products are sold to consumers. The products are used until the end of the designed life-cycle and finally thrown them away. Large amounts of waste are the direct consequences of consumption that exceeds real needs and at the same time, alters the state of the environment.

In order to diminish the impact of the waste, even in the conception phase of a product, the designer must find a solution for design and production in a way that allows continuous re-use of resources.

The introduction of the circular economy is a challenge to the linear economy approach for both the production and consumption of resources. The circular economy is an economy that produces zero waste. 
The circular economy has two ideas, the first regarding the flow of materials through an economy and the second is concerned with thinking about the economic conditions that could generate such a flow.

The transition process from a linear economy to a circular economy has brought many barriers and challenges, [2]. Kayikci et al. believe that smartness, sustainability, and circularity need to be intertwined and adapted by companies. In their paper, the authors present the concept of Smart and Sustainable Circular Economy - SSCE at the macro-level and address the barriers of this concept under four main aspects: technology, producers, consumers, and policy. These aspects are investigated for small and medium-sized enterprises of an Eco-Cluster in the automotive industry.

In circular economy-based models, the resources stay in the system as it experiences one of the $10 \mathrm{R}$ (Refuse, Rethink, Reduce, Reuse, Repair, Refurbish, Remanufacture, Repurpose, Recycle, and Recover) processes, [3], [4].

Based on a literature review, in paper [5], the authors aim to identify the roles of digital technologies supporting the Circular Economy. They propose to evaluate the relationship between Circular Economy and digital technologies by using Business Model Canvas integrating the R-principles such as reuse, remanufacture, and recycle.

The core ideas of circular economy are the elimination of waste by design, respect for the social, economic, and natural environment, and resourceconscious business conduct, [6]. The authors seek in [7] to revisit the concept of circular economy in the manufacturing industry in order to determine whether the research body has moved beyond concept development and into verified implementation in the industry. In [8] by applying the circular economy at the local level, new production models could have experimented yielding the chance of regenerating the urban context and redesigning the concept of sustainability and well-being. Paper [9] describes the development of a circular economy readiness selfassessment tool, MATChE - Making the Transition to a Circular Economy, following iterative cycles of theoretical development and empirical codevelopment with potential users. Braz and Mello proposed in [10] an innovative framework characterizing circular economy supply network management as a complex adaptive system leading to three different configurations: a closed-loop supply network, an open-loop supply network, and a combination of both, adding new industries' supply chains and nonlinear connections and resulting in a hybrid loop supply network. In paper [11], a model was developed to explore the relationships between social pressure, environmental commitment, green economic incentives, supply chain relationship management, sustainable supply chain design, and circular economy capability, applying the confirmatory factor analysis (CFA).
This paper presents an image on the degree of knowledge of the circular economy concept, highlighting the major discrepancies between the linear and circular economy and the multidisciplinary impact of implementing the circular economy.

The circular economy is a fundamental change in the traditional model of the economy by achieving a balance between economy, resources, and environment. Also, this paper analysed from a theoretical point of view, the transition process of economic organizations from the linear economy to a circular economy.

The transition to a circular economy can bring the following benefits: improved environmental conditions, improved supply of raw materials, increased competitiveness, stimulated innovation, stimulated growth, and new jobs.

The paper is divided into five sections. Following this introduction, Section II outlines the concept of circular economy and its principles. Section III shows the linear economy versus the circular economy. In section IV, a study is being developed on the transition of companies from the linear economy to the circular economy. Finally, section $\mathrm{V}$ presents the paper's conclusions.

\section{CIRCULAR ECONOMY: THE CONCEPT AND ITS PRINCIPLES}

In scientific literature and professional journals use many definitions for the circular economy. The most renowned definition has been framed by the Ellen MacArthur Foundation, introducing the Circular Economy as "an industrial economy that is restorative or regenerative by intention and design", [12], [13].

The circular economy, an evolving concept, is considered a necessary and pragmatic solution for reconciling the link between the growth rate and pressure on the environment's resources, [14].

The circular economy can be understood as an idea and ideal for facing the increasing limitations of Earth's natural resources, facing the limitations as a new path to the transition to production and consumption for sustainability, [15].

The circular economy is a model of production and consumption, which involves sharing, leasing, reusing, repairing, refurbishing, and recycling existing materials and products as long as possible aiming to tackle global challenges like climate change, biodiversity loss, waste, and pollution, [16].

The circular economy is an economic model that covers supply chains and sectors and redefines the process of designing, manufacturing, and consuming products, thus opening up new, untapped (secondary) markets for companies.

The concept of circular economy has been developed from a multidisciplinary perspectives thanks to different approaches from disciplines such as ecology, economy, engineering, design, and business, [17]. 
The path that society has traveled to the CE can be divided into three major stages (Figure 1).

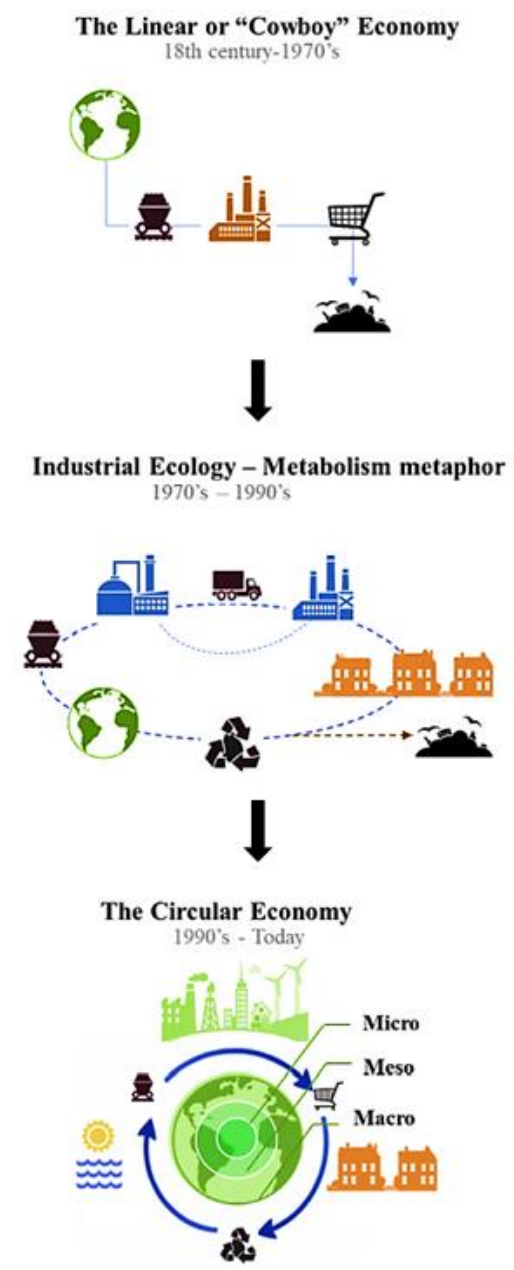

Fig. 1. Circular economy knowledge map, [17]

The first stage is the linear economy, which began with the industrial revolution and overexploitation of resources. A second stage begins with the awakening of the first theoretical and practical initiatives of industrial ecology. In this stage, interest in a greener economy emerged. The third stage starts at the beginning of the '90s when Pearce and Turner following Bounding's research, coined the term circular economy to explain the feasibility of taking into account environmental awareness in economic flows by closing industrial loops, [17].

The circular economy model is based on three principles [18]:

i) Conservation and consolidation of natural capital,

ii) Optimizing resources consumption, and

iii) Promoting the efficiency of the system.

Each principle responds to the many challenges facing the industrial sectors regarding resources and the system.

The first principle, namely the conservation and consolidation of natural capital by controlling finite stocks and balancing the flow of renewable resources refers to the design of waste, the reduction of the use of non-renewable natural resources, and the encouragement of the use of renewable materials. This can be done by:

- dematerialization - replacement of products, when possible, with a service (product service systems),

- smart materials - the choice of materials that last and for the processing of which a small amount of energy and renewable energy is consumed, and

- facilitating ecosystems - ecosystems are balanced by extracting and introducing nutrients at the right place and time.

The second principle, namely optimizing resource consumption through the circulation of products, components, and materials used in cyclical technical and biological processes, means that products can be repaired, prefabricated, recycled when their performance or function is damaged or when the designed life-cycle is finished. This principle increases the useful life of the product or component/material to drive good quality recycled products.

The third principle, namely promoting the efficiency of the system by designing and presenting how to reduce the negative effects, refers to the reduction of the negative effects of the use of resources on the health of customers, on education or food, [18].

\section{CIRCULAR ECONOMY VERSUS LINEAR ECONOMY}

The economy is key to fighting climate change. That is why we must continue the shift from a linear to a circular economy to make sure society progresses in a way that is environmentally friendly, [19].

The circular and linear economies are two paths that drive the industry wheel of production.

In recent years, the circular economy has gained significant momentum in response to the wasteful linear system.

To explain the circular economy, the simplest analogy is with the linear economy. In a linear economy, the simplified principle is: take, make and dispose.

In a circular economy, we try to keep in use as much as possible something that is produced through repairs and, subsequently, to recycle in order to be able to take the cycle from the beginning, preventing the production of large amounts of waste.

The circular economy means the transition to an economy based on the reduction of energy and raw materials consumption, in which the resulting waste has precise destinations from the design phase, being integrated in the cyclical spiral of reuse.

The wastes that occur in one manufacturing process should be raw materials for another process, through the implementation of appropriate green technologies. 
The linear economy model is presented in Figure 2.

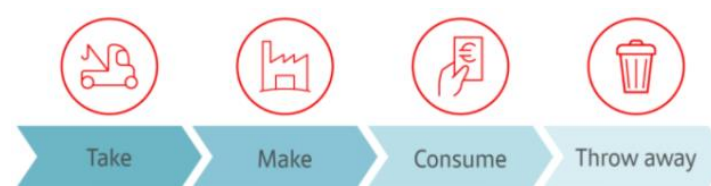

Fig. 2. The linear economy model, [19]

As illustrated in Figure 2, such economic model is characterized by the take, make, waste pattern and is built on two strong assumptions: boundlessness and easy availability of resources (energy and raw materials) as well as a limitless regenerative capacity of the Earth. Accordingly, as the economy grows, we need more raw materials for the production of goods and we produce more waste, [20].

The transition to the circular economy model is to be made, allowing more efficient use of resources. The circular economy model is presented in Figure 3.

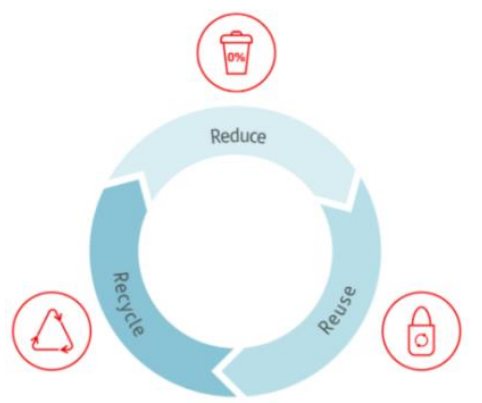

Fig. 3. The circular economy model, [19]

Figure 3 illustrates in a simplified way the main phases of a circular economic model, in contrast to a traditional linear economy. In this conceptual diagram, each phase presents opportunities in terms of reducing costs and dependence on natural resources as well as limiting waste and harmful emissions to the environment, [20].

The circular economy compared to the linear economy works in a far smoother and more sustainable way. The main focus of this economy is to maintain the added value of material while eliminating waste as best as possible. The circular economy is concentrated on the usage of products as resources.

The method used by the circular economy is actually the $3 \mathrm{R}$ principle:

- reduce,

- reuse, and

- recycle, [21].

Resource used is minimized (reduce). Reuse of products and parts is maximized (reuse). Raw materials are reused (recycled) to a high standard.

In the circular economy, recycled materials are recovered from end-of-life products, which are then reused as raw materials in other end-of-life products. In this way, waste and its impact on the environment are reduced, resulting in reductions in production costs.
The circular economy means closing the loop of the value chain, from production to consumption, by:

- repair and remanufacturing activities,

- management of waste and secondary raw materials that are reintroduced into the economy.

The circular economy is more profitable and less harmful to the environment and its main goals include sustainable economic growth, increased competitiveness, and new jobs.

\section{CASE STUDY - THE TRANSITION TO A CIRCULAR ECONOMY}

The world's population is growing, as is the demand for raw materials. However, the supply of crucial raw materials is limited. Finished supplies mean that some EU countries depend on other countries for raw materials. In addition, the extraction and use of raw materials have a major impact on the environment. It also increases energy consumption and $\mathrm{CO}_{2}$ emissions. Smarter use of raw materials can reduce $\mathrm{CO}_{2}$ emissions.

More and more companies are experiencing how the circular economy can help them to analyse customer needs and expectations and design the products taking into account the environment and waste management.

The case study presents an image of the familiarity degree with the concept of the circular economy of companies. In this context, a questionnaire was developed containing a number of 15 questions. The first part of this questionnaire contains questions related to the company, namely the field of activity, the number of employees. The second part of the questionnaire includes questions related to the circular economy, the management system currently used in the company, the impact of the implementation of the circular economy, and the benefits obtained from its implementation, in case the concept of circular economy was implemented.

The questionnaire was developed in MS Forms. 50 companies received the link to complete the questionnaire through email and took part in this study.

The participating companies were mainly from the sectors of industrial production, transport, recycling and waste management, textiles and clothing. Onethird of those surveyed work in companies with fewer than 250 employees, while the rest work in companies with more than one employee.

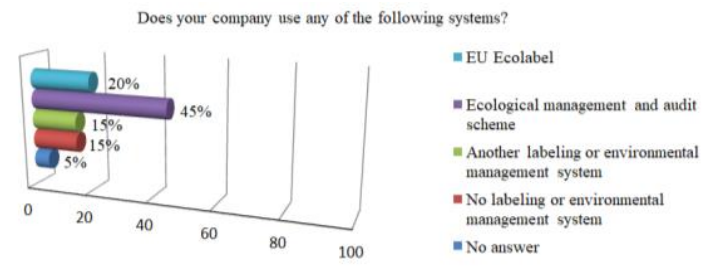

Fig. 4. Systems of environmental management used by the interviewed companies 
Table 1. Analysis of the answers according to figure 4

Regarding the systems used within companies

- $45 \%$ of the respondents use ecological management and audit schemes within the company,

- $20 \%$ use the ecological label, and

- $15 \%$ use another labelling or environmental management system.

Is the energy management system implemented in your company?

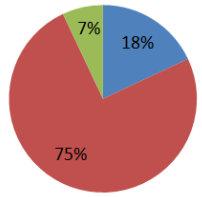

- Yes

- No

Under implementation

Fig. 5. Implementation of energy management system within companies

Table 2. Analysis of the answers according to figure 5

Regarding implementing the energy management system

- $18 \%$ of the interviewed companies stated that they have implemented the energy management system,

- $75 \%$ have not yet implemented this system, and

- $7 \%$ are in the process of implementation.

Do you think you are familiar with the concept of circular economy?

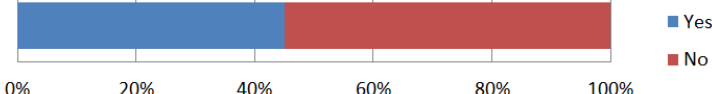

Fig. 6. Familiarization with the concept of circular economy

Table 3. Analysis of the answers according to figure 6

Regarding the familiarization with the concept of circular economy

- $45 \%$ of the interviewed companies are familiar with the concept of circular economy, and

- $55 \%$ of those surveyed have not yet heard of the circular economy.

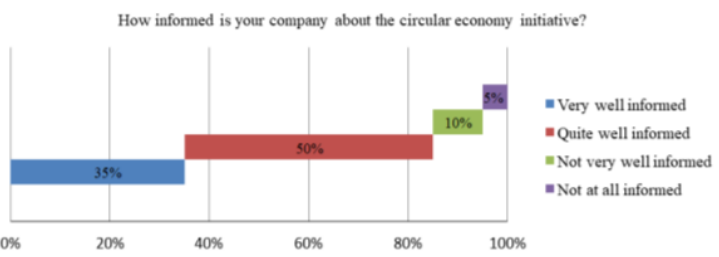

Fig. 7. Knowledge of the circular economy initiative
Table 4. Analysis of the answers according to figure 7

Regarding the circular economy initiative

- $35 \%$ of the interviewed companies are very well informed,

- while $50 \%$ are quite informed, and

- only $15 \%$ are not very informed or not at all regarding the circular economy initiative.

Is the transition to a circular economy integrated into the company's development strategies or plans?

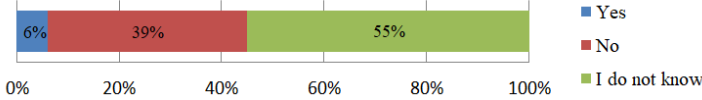

Fig. 8. Integrated the transition to the circular economy

Table 5. Analysis of the answers according to figure 8

Regarding integration of transition to the circular economy

- only $6 \%$ of respondents have integrated the transition to the circular economy into the company's development strategies or plans,

- while $39 \%$ have stated that the transition to a circular economy is not integrated.

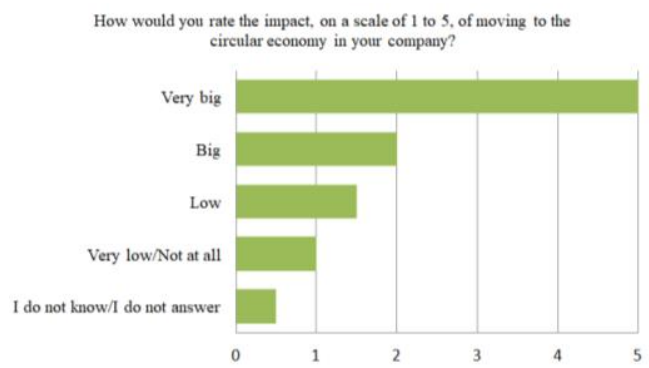

Fig. 9. Assessing the impact of the transition to the circular economy

Table 6. Analysis of the answers according to figure 9

Regarding the impact of the transition to the circular economy

- only $50 \%$ of the surveyed companies consider that this transition has a very high impact on their company,

- while $15 \%$ of those surveyed believe that the transition to the circular economy will have a low impact on their company.

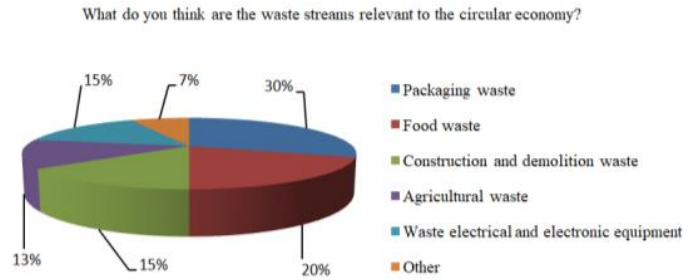

Fig. 10. Waste streams for the circular economy 
Table 7. Analysis of the answers according to figure 10

\begin{tabular}{l} 
Regarding the waste stream relevant to the \\
circular economy \\
\hline - only $30 \%$ of the surveyed companies \\
consider that the largest waste stream comes \\
from packaging.
\end{tabular}

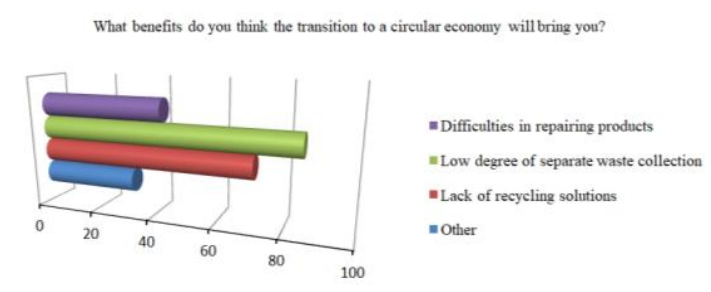

Fig. 11. The benefits of moving to the circular economy

Table 8. Analysis of the answers according to figure 11

Regarding the benefits of moving to the
circular economy

The transition from the linear economy to the circular economy is an opportunity to provide solutions and products that meet the needs of current and future generations, related to: performance, sustainability, and protect of the planet's future.

The study shows that successful implementation of circular strategies is possible and it is not dependent on the size of the company or field of activity/industry.

The leaders of circular models are differentiated by the strategic attention they pay to circular activities, quantified targets, and partnerships between industries, as well as contracts with investors and policymakers.

The interviewed companies consider that the circular economy is the next necessary step for the world to move towards a sustainable future.

The transition to the circular economy depends on the ability of companies to develop that organizational culture that ensures the balance between exploiting current knowledge by continuously improving the current business model and exploiting new opportunities by innovating the current business model.

Companies need to integrate, build and configure internal and external skills and capabilities to address the new environmental dynamics. The aspirations of the circular economy require the innovation of current business models, but the results provided by innovation are unpredictable and far-fetched, and innovation can also lead to considerable successes and significant failures.

According to the study, the majority of surveyed companies openly embrace the idea of a circular economy, but in reality, many of them do not want to go through the series of experimental failures needed to get there. Innovation is associated with high costs and risks.

\section{CONCLUSIONS}

From the study presented in this paper, the following conclusions can be drawn:

- The circular economy aims to close some materials flows through adequate technical-productive processes, a problem long treated under the form of integration of production and the active circular process.

- The circular economy is a result of economic thinking that has revolutionized the pessimism of an overpopulated and impoverished society as a result of depletion of resources to a balanced economy, which also addresses economic growth, environmental issues, and social relations to ensure the quality of life.

- The circular economy describes a business model based on the design/manufacture/distribution and consumption of goods works, services through the reduction, reuse, recycling, and extraction of materials.

- The interviewed companies consider that the circular economy is the next necessary step for the world to move towards a sustainable future.

- Companies need to integrate, build, and configure internal and external skills and capabilities to address the new environmental dynamics.

- According to the study, the majority of surveyed the companies embrace the idea of circular economy, but in reality, many of them do not want to go through experimental failures to get there.

- To ensure their success in a circular economy, companies must strategically integrate exploitation and exploration activities and capture the benefits generated by them in a similar way.

- The transition to a circular economy can bring the following benefits:

○ Improving environmental conditions;

- Improving the supply of raw materials;

- Increasing competitiveness;

- Stimulating innovation;

- Stimulating economic growth;

$\circ$ Creating new jobs.

\section{ACKNOWLEDGEMENTS}

This work was supported by the Romanian Ministry of Research and Innovation, CCCDI -UEFISCDI, project number PD-III-P1-1.2-PCCDI-2017-0446 / Intelligent manufacturing technologies for advanced production of parts from automobiles and aeronautics industries (TFI PMAIAA) - 82 PCCDI/2018, within PNCDI III.

\section{REFERENCES}

[1] C. Negrei and N. Istudor, „Circular economy - between 
theory and practice", Amfiteatrul Economic, vol. 20, no. 48, pp. 498-509, 2018

[2] Y. Kayikci, Y. Kazancoglu, C. Lafci, N. Gozacan „Exploring barriers to smart and sustainable circular economy: The case of an automotive eco-cluster", Journal Cleaner Production, vol. 314, no. 127920, pp. 1-14, 2021.

[3] S. Bag, S. Gupta, S. Kumar, „Industry 4.0 adoption and 10R advance manufacturing capabilities for sustainable development", International Journal of Production Economics, vol. 231, no. 107844, pp. 1-12, 2021.

[4] E. Uçar, M. A. Le Dain, I. Joly, „Digital Technologies in Circular Economy Transition: Evidence from Case Studies", Procedia CIRP, vol. 90, pp. 133-136, 2020.

[5] B. Kayal, D. Abu-Ghunmi, L. Abu-Ghunmi, A. Archenti, M. Nicolescu, C. Larkin, S. Corbet, „An economic index for measuring firm's circularity: The case of water industry", Journal of Behavioral and Experimental Finance, vol. 21, pp. 123129, 2019.

[6] F. Sariatli, „Linear Economy Versus Circular Economy: A Comparative and Analyzer Study for Optimization of Economy for Sustainability", Visegrad Journal on Bioeconomy and Sustainable Development, vol. 6, no. 1, pp. 31-34, 2017.

[7] M. M. Bjørnbet, C. Skaar, A. Magerholm Fet, K. Øverbø Schulte, „Circular economy in manufacturing companies: A review of case study literature", Journal of Cleaner Production, vol. 294, no. 126268, pp. 1-14, 2021

[8] S. K. van Langen, C. Vassillo, P. Ghisellini, D. Restaino, R. Passaro, S. Ulgiati, „Promoting circular economy transition: A study about perceptions and awareness by different stakeholders groups", Journal of Cleaner Production, vol. 316, no. 128166, pp. $1-22,2021$

[9] D. Pigosso, T. McAloone, ,Making the transition to a Circular Economy within manufacturing companies: the development and implementation of a self-assessment readiness tool", Sustainable Production and Consumption, vol. 28, pp. 346358, 2021.
[10] A. C. Braz, A. M. del Mello, „Circular economy supply network management: A complex adaptive system", International Journal of Production Economics, vol. 243, no. 108317, pp. 1-12, 2022.

[11] P. Centobelli, R. Cerchione, E. Esposito, R. Passaro, Shashi, „Determinants of the transition towards circular economy in SMEs: A sustainable supply chain management perspective", International Journal of Production Economics, vol. 242, no. 108297, pp. 1-14, 2021.

[12] M. Geissdoerfer, P. Savaget, N. Bocken, E. J. Hultink, „The Circular Economy - A new sustainability paradigm?", Journal of Cleaner Production, vol. 143, pp. 757-768, 2017.

[13] https://ellenmacarthurfoundation.org/topics/circulareconomy-introduction/overview.

[14] C. Căutișanu, L. Asandului, M. Borza, C. Turturean, "Quantitative approach to circular economy in the OECD countries", Amfiteatru Economic, vol. 20, no. 48, pp. 262-277, 2018.

[15] A. S. Homrich, G. D. A. Galvão, L. Gamboa, M. M. de Carvalho, „The Circular Economy Umbrella: Trends and Gaps on Integrating Pathways", Journal of Cleaner Production, vol. 175, pp. 525-543, 2018.

[16] https://en.wikipedia.org/wiki/Circular_economy.

[17] V. Prieto-Sandoval, C. Jaca, M. Ormazabal, „Towards a consensus on the circular economy", Journal of Cleaner Production, vol. 179, pp. 605-615, 2018

[18] „Circular economy - Support material”. p. 50, 2019

[19] https://www.santander.com/en/stories/linear-and-circulareconomies-what-are-they-and-whats-the-difference.

[20] T. Wautelet, ,Exploring the role of independent retailers in the circular economy: a case study approach", Thesis for Master of Business Administration, University for Economics \& Management, 2018.

[21] https://impacx.io/blog/circular-economy-vs-lineareconomy/. 